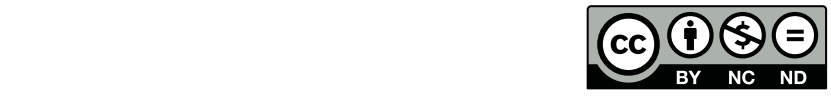

Estudos Teológicos foi licenciado com uma Licença Creative Commons Atribuição - NãoComercial - SemDerivados 3.0 Não Adaptada

http://dx.doi.org/10.22351/et.v.57i2.2670

\title{
A espiritualidade e a medicina integrativa NO CONTEXTO DA SAÚDE INTEGRAL DO SER HUMANO ${ }^{1}$
}

\author{
The spirituality and the integrative medicine \\ in the context of the human integral health
}

\section{Flávio da Silva Chaves ${ }^{2}$ Francisco de Assis Souza dos Santos ${ }^{3}$}

Resumo: As pesquisas apontando a relação entre saúde e espiritualidade vêm crescendo de forma progressiva. O objetivo deste trabalho é fazer as devidas diferenciações conceituais entre os termos religião, religiosidade e espiritualidade e apresentar sua relevância no contexto da saúde física e psíquica em diálogo com o novo modelo médico, a medicina integrativa. A metodologia utilizada para a construção deste trabalho foi a revisão bibliográfica de literatura. Os resultados apontam que há diferenciações nos termos religião, religiosidade e espiritualidade. A medicina integrativa, mediante a visão holística do ser humano, preconiza uma abordagem multidisciplinar e interdisciplinar no processo de cura dos pacientes. Por isso foi considerado o coping religioso como estratégia de enfrentamento nos mais variados dilemas da vida. Conclui-se que a definição contemporânea sobre religião/religiosidade/ espiritualidade se volta mais para a vivência da religião do que para os seus aspectos institucionais. A espiritualidade não institucional, desvinculada das tradições religiosas, poderá ser benéfica tanto para o físico como para a psique humana. Tal assertiva contribuirá para o processo de humanização do indivíduo e com o diálogo entre outros campos do saber, dentre esses, o novo modelo médico, a medicina integrativa.

Palavras-chave: Espiritualidade. Saúde integral. Coping religioso. Medicina integrativa.

1 O artigo foi recebido em 16 de janeiro de 2016 e aprovado em 22 de julho de 2017 com base nas avaliações dos pareceristas ad hoc.

2 Mestre em Ciências das Religiões pela Faculdade Unida de Vitória (FUV, Vitória/ES, Brasil) sob a orientação do Dr. Francisco de Assis Souza dos Santos; pós-graduando Lato Sensu em Fenomenologia Existencial e Gestalt terapia pelo Isecensa; especialista em Gestão Ministerial pela Faberj; graduado em Psicologia pela Universidade Estácio de Sá; graduado em Teologia pela Faculdade Unida de Vitória. É psicólogo clínico; pastor batista atuando em Comunidade de Risco Social; é professor de Introdução ao Antigo Testamento; Teologia Bíblica do Antigo Testamento e Psicologia do Desenvolvimento na Faberj (Faculdade Batista do Estado do Rio de Janeiro). Contato: flavio.chaves.silva@hotmail.com

3 Professor da Faculdade Unida de Vitória, em Vitória/ES, Brasil. Doutorado pela PUC-Rio na área de Teologia Sistemática; mestre em Teologia Prática pela Escola Superior de Teologia - EST, São Leopoldo/ RS, área de concentração Aconselhamento Pastoral. Formação em Psicanálise pela Escola Brasileira de Psicanálise - Delegacia ES. Pós-graduação em Teoria Psicanalítica na Faculdade Unida de Vitória; pós-graduação em Estudos Linguísticos na Universidade de São Paulo; graduação em Línguas Letras Português na Universidade Federal do Espírito Santo - UFES. Contato: chiquinhovinde@gmail.com 
Abstract: Research indicates that the relationship between health and spirituality has been growing in a progressive way. The objective of this study is to make the appropriate conceptual differences between the terms religion, religiosity and spirituality and to present its relevance in the context of physical and psychic health in dialogue with the new medical model, integrative medicine. The methodology used for the construction of this work was the bibliographical review of the literature. The results indicate that there are differences between the terms religion, religiosity and spirituality. Integrative medicine, through the holistic vision of the human being, advocates a multidisciplinary and interdisciplinary approach in the healing process of patients. Therefore, religious coping was considered as a coping strategy in the most varied dilemmas of life. The conclusion is that the contemporary definition of religion/religiosity/spirituality turns more to the experience of religion than to its institutional aspects. Non-institutional spirituality, unrelated to religious traditions, can be beneficial to the physical as well to the human psyche. This assertion will contribute to the process of humanization of the individual and to the dialogue among other fields of knowledge, among them, the new medical model, integrative medicine.

Keywords: Spirituality. Integral health. Religious coping. Integrative medicine.

\section{Introdução}

A partir desta pesquisa, busca-se refletir sobre a relação da espiritualidade e a medicina integrativa no contexto de saúde integral do ser humano. Para tanto, percorrem-se três caminhos na elucidação da questão. Num primeiro momento são apresentadas as diferenciações entre os termos religião/religiosidade e espiritualidade. Percebe-se, na discussão, que é a vivência da religião e não seus aspectos institucionais que poderá contribuir para o equilíbrio físico e psíquico do indivíduo.

O contexto contemporâneo é marcado pelo biologicismo e pelo poder médico, dificultando pensar a espiritualidade enquanto interventora no processo de cura do indivíduo. Por isso propõe-se, em um segundo momento, pensar a quebra do paradigma do modelo biomédico. A proposta é inserir a medicina integrativa enquanto proposta de intervenção no contexto da saúde para, então, pensar a espiritualidade e seus benefícios, considerando o coping religioso.

Por último, são apresentados alguns resultados da espiritualidade na intervenção da saúde física e psíquica do ser humano. Nesse sentido, numa perspectiva multidisciplinar e interdisciplinar, a espiritualidade poderá dialogar com outros campos do saber, dentre esses, a medicina integrativa. Tal diálogo é o que se propõe pensar nessa pesquisa.

\section{Religião, religiosidade ou espiritualidade?}

Os termos religião/religiosidade/espiritualidade apresentam-se de formas diferenciadas entre os autores. O psicólogo Geraldo José Paiva, ao falar sobre psicologia e espiritualidade, apresenta as formas como eram consideradas e como elas se apre- 
sentam na contemporaneidade, destacando a espiritualidade humanista como a mais utilizada hoje, abarcando até a espiritualidade ateia. ${ }^{4}$

Há uma oposição de conceito entre religião e espiritualidade:

Por religião veio a entender-se a instituição, a autoridade, a comunidade, os dogmas, os ritos litúrgicos, a ética dos mandamentos, com as correspondentes atitudes de obediência, aceitação, participação coletiva, comportamento moral e culpa. Por espiritualidade veio a entender-se o indivíduo, a criatividade, a experiência pessoal principalmente afetiva, os grupos de livre escolha, as celebrações espontâneas e a inserção ecológica, com os sentimentos de liberdade, autenticidade, conexão ${ }^{5}$.

Todavia, na mesma pesquisa, são apresentadas divergências e convergências conceituais entre religião e espiritualidade. Apropriando-se da análise de Saroglou, Paiva afirma que:

Embora religiosidade clássica e espiritualidade possam se opor no nível das representações, os processos psicológicos implicados no comportamento religioso ou espiritual apresentam matizes e intensidades diferentes, sobressaindo mais uma gradação do que uma oposição de processos ${ }^{6}$.

Coadunando com o pensamento acima, Faria e Seidl ${ }^{7}$, conforme Lukoff, distinguem o termo religiosidade de espiritualidade, "definindo a primeira como adesão a crenças e práticas de uma igreja e instituição religiosa organizada, e a segunda como a relação estabelecida por uma pessoa com um ser ou uma força superior na qual ela acredita". Citando Spilka e McIntosh, afirmam que

a conceituação de religiosidade inclui aspectos individuais e institucionais, enquanto espiritualidade é um fenômeno apenas individual, identificado com aspectos como transcendência pessoal, sensibilidade "extraconsciente" e fontes de sentidos para eventos da vida ${ }^{9}$.

Já Muller, ao definir espiritualidade, apresenta-a como elemento constitutivo do ser humano. Alinha ao conceito termos como vitalidade e novas formas de olhar o mundo, onde o ser humano vai construindo sua integralidade e sua integração com tudo que o cerca:

4 PAIVA, Geraldo José de. Psicologia e Espiritualidade. In: BERGER, Andrea Simone; TINOCO, Denise Hernandes; ABOU CHAHINE, Marien (Orgs.). Encontros na Psicologia. IV Congresso de Psicologia Unifil. I Congresso Nacional de Psicologia. Londrina: Ed. Unifil, 2011. p. 15-22.

5 SARAGLOU, 2003 apud PAIVA, 2011, p. 2.

6 PAIVA, 2011, p. 17.

7 FARIA, Juliana Bernardes; SEIDL, Eliane Maria Fleury. Religiosidade e enfrentamento em contextos de saúde e doença: revisão da literatura. Psicologia: Reflexão e Crítica, 2005, v. 18, n. 3, p. 381-389, 2005. p. 381 .

8 FARIA; SEIDL, 2005, p. 381.

9 FARIA; SEIDL, 2005, p. 381. 
Espiritualidade é viver com espírito e, portanto, é uma dimensão constitutiva do ser humano. Espiritualidade é uma expressão para designar a totalidade do ser humano enquanto sentido e vitalidade, por isso espiritualidade significa viver segundo a dinâmica profunda da vida. Isso significa que tudo na existência é visto a partir de um novo olhar onde o ser humano vai construindo a sua integralidade e a sua integração com tudo que o cerca $^{10}$.

Embora Faria e Seidl apresentem os pontos divergentes de conceitos entre espiritualidade e religiosidade, sua pesquisa optou por considerar os termos relativos à religiosidade, como religião e religioso(a), abarcando tanto aspectos individuais como institucionais. ${ }^{11}$ Ruthes, em contraposição ao pensamento desses autores, postula que houve uma mudança de conceito no termo espiritualidade entre o início do século XX e a metade do mesmo século. Se no início do século XX “a Espiritualidade estava diretamente ligada à visão de mundo das religiões" 12 , a partir da metade do século começa um novo período histórico, denominado por ela de pós-moderno. Com isso, surge um novo modo de perceber e de viver a espiritualidade, conforme descrito abaixo:

Esta tem sua origem na ideia de um mundo que vive um contexto histórico impactado pelas mudanças no contexto social, existencial e valorativo posterior à II Guerra Mundial. Sua característica principal é a descrença nas metanarrativas, nas grandes ideologias que legitimavam os saberes, as sociedades, os sentidos da existência. Tal processo gera impacto de maneira pontual e incisiva, não apenas na compreensão de mundo, mas no caso específico deste artigo, na compreensão do conceito de espiritualidade. É interessante perceber que a espiritualidade foi dissociada, nessa perspectiva, da vivência de uma religião. Ela está ligada à necessidade da vivência existencial que procura uma relação com algo que transcenda a realidade, considerando-o sagrado ${ }^{13}$.

"Um sincretismo de valores, símbolos, práticas é criado para fundamentar uma forma de ser espiritual, a qual é baseada em algumas características genéricas." $14 \mathrm{O}$ cultivo da bondade, da tolerância, do respeito à diversidade bem como o cuidado com o ecossistema visando à sustentabilidade são novas formas de definir e vivenciar a espiritualidade.

Na perspectiva de Peçanha e Silva, o construto de espiritualidade aborda temas como "realidade existencial, envolvimento e poder/força/energia e transcendência". Nesse sentido, a espiritualidade seria entendida como

uma jornada pessoal para descobrir o sentido da vida, em que a pessoa aprende a enfrentar medos, lidar com o desconhecido, encarar a mortalidade; ao mesmo tempo em que

${ }^{10}$ MULLER, Marisa Campio. Introdução. In: TEIXEIRA, Evilázio Francisco Borges et al. (Orgs.). Espiritualidade e qualidade de vida. Porto Alegre: EDIPUCRS, 2004. p. 8.

11 FARIA; SEIDL, 2005, p. 382.

12 RUTHES, Vanessa Roberta Massambani. A relação entre espiritualidade e saúde: um novo paradigma. Saberes em Ação. Revista de Estudos da Faculdade Messiânica, ano 2, n. 3, p. 8-13, jan./jun. 2014. p. 8.

13 RUTHES, 2014, p. 9.

14 MURAD, 2007 apud RUTHES, 2014, p. 9. 
ama, perdoa, e conforta outros [...]. Espiritualidade transcende o presente contexto da realidade e existe através e independente de tempo e espaço. Para eles a espiritualidade pode ser um indicador da capacidade humana de transcendência [...]. Espiritualidade também tem sido definida como energia criativa, motivação, conselhos e esforço para inspiração. É um dinâmico, integrativo, crescente e muito importante processo para alcançar atingir o propósito e sentido da vida ${ }^{15}$.

Underwood e Teresi diferenciam categoricamente os construtos espiritualidade versus religiosidade afirmando:

Religiosidade tem características comportamentais, sociais, doutrinárias e denominacionais porque envolve um sistema de pessoas e doutrinas que é compartilhado por um grupo. Espiritualidade está envolvida com a transcendência, com o lidar com questões finais sobre o sentido da vida, com a aceitação de que há mais vida do que podemos ver ou entender completamente. Espiritualidade pode nos chamar para o envolvimento com o eu, para se preocupar e ter compaixão com os outros. Enquanto a religião tenta influenciar para encorajar e prover a vida espiritual - e a espiritualidade é normalmente um aspecto saliente da participação religiosa - é possível adotar formas de encontros religiosos e doutrinas sem ter um forte relacionamento com o transcendental ${ }^{16}$.

Na pesquisa de Peçanha e Silva, é apresentado um dado interessante e novo: ao mesmo tempo em que são mostradas diferenciações no construto entre religiosidade versus espiritualidade, não é descartada a religião em termos institucionais. No dizer das autoras, a espiritualidade "pode remeter a muitas imagens"17, o que envolve "várias expressões da espiritualidade, cada uma empacotada segundo o critério de uma tradição religiosa" ${ }^{18}$. Mas afirmam veementemente que é a espiritualidade intrínseca que tem sua relevância para a saúde física e mental:

Mas é a espiritualidade, entendida por alguns pesquisadores como religião intrínseca, que relaciona-se com a saúde física e mental. A religiosidade extrínseca pode ser expressa por exemplo em uma comunidade religiosa como oferecedora de suporte para o indivíduo, mas o uso extrínseco da religião, o tornar-se religioso só para atingir saúde não resulta em correlações positivas com a saúde mental ${ }^{19}$.

Nessa perspectiva de espiritualidade intrínseca, o pastor Tom Hovestol ${ }^{20}$ pondera os efeitos negativos de uma religião farisaica. A partir de uma análise da religiosidade dos fariseus, nos tempos de Jesus, apresenta os motivos pelos quais aqueles,

\footnotetext{
15 PEÇANHA, Dóris Lieth; SILVA, Priscila Menezes da. Saúde mental: estudos sobre a contribuição da espiritualidade. Universidade Federal de São Carlos, Centro de Educação em Ciências Humanas, Departamento de Psicologia, 2005. p. 5, 7.

16 UNDERWOOD; TERESI, 2002 apud PEÇANHA; SILVA, 2005, p. 8.

17 PEÇANHA; SILVA, 2005, p. 9.

18 PEÇANHA; SILVA, 2005, p. 9.

19 PEÇANHA; SILVA, 2005, p. 9.

${ }^{20}$ HOVESTOL, Tom. A neurose da religião: o desastre do extremismo religioso! São Paulo: Hagnos, 2009. p. $23-72$.
} 
sendo tão bons crentes, sofreram críticas por parte do Senhor Jesus Cristo. Dentre os motivos, destaca-se o comportamento externo em detrimento da transformação do coração, ou seja, um modelo de religião associado a uma visão desdenhosa dos outros, um senso superficial de perdão, um senso equivocado de graça e justiça, uma visão doentia de fracasso, reiterando, sob o olhar da parábola do samaritano, a importância de uma espiritualidade centrada na compaixão.

Com base nas propostas de Gianni Vattimo, Vieira ${ }^{21}$ apresenta uma espiritualidade que está "entre e além de concepções religiosas" 22 , fazendo emergir um novo conceito de espiritualidade, denominada de pós-metafísica. Sua reflexão versa sobre a crise contemporânea que ocorreu no cristianismo por não entender seu contexto e por utilizar, em seu discurso, uma "'metafísica forte', conduzindo seus fiéis a um processo de "esquizofrenia cristã" 23 . O autor afirma que a "religiosidade cristã, na contemporaneidade, perdeu o foco e a centralidade no Cristo que fez de sua vida e missão uma práxis pela caridade" 24 . A base epistemológica de Vattimo, segundo Vieira, é a substituição do "pensamento forte" (ou tradição metafísica) pelo "pensamento fraco". Nesse sentido, há um deslocamento do pensamento iluminista que propôs uma "verdade que fundamenta a existência do Ser, proporcionado pelas formas tradicionais" 25 , para uma nova maneira de pensar do ser humano moderno, provocada pelo avanço da tecnologia. ${ }^{26}$

Sob a proposta de uma hermenêutica niilista de Gianni Vattimo, Rosa aponta para um conceito de espiritualidade "tomando como ponto de partida o conceito de Kênosis como referencial de fragilidade"27. O autor apresenta "a ideia de um Deus que se esvazia, se autolimita e se fragiliza"28, propondo "novos caminhos de vivência da espiritualidade cristã" 29 . Nessa hermenêutica, abandona-se o absolutismo, a verdade fundante, substituindo por um pensamento fraco, a partir do conceito da morte de Deus em Nietzsche. ${ }^{30}$ Abordam-se novas possibilidades de se pensar a espiritualidade, pautadas no diálogo e em novas interpretações. ${ }^{31} \mathrm{O}$ exemplo é a Kênosis de Jesus Cristo, uma espiritualidade que "se revela pelos seus compromissos éticos. Uma espiritualidade cidadã. Uma espiritualidade não religiosa" ${ }^{32}$, reiterado por Zabatiero, a

${ }^{21}$ VIEIRA, Carlos Alberto Pinheiro. A proposta de Gianni Vattimo para uma espiritualidade pós-metafísica. Paralellus, Recife, ano 3, n. 1, p. 189-204, jul./dez. 2012.

22 VIEIRA, 2012, p. 189.

${ }^{23}$ VIEIRA, 2012, p. 190.

${ }^{24}$ VIEIRA, 2012, p. 190.

${ }^{25}$ VIEIRA, 2012, p. 190, 191.

${ }^{26}$ COSTA, 2008 apud VIEIRA, 2012, p. 194.

27 ROSA, Wanderley Pereira da. Kênosis e espiritualidade: uma leitura a partir do pensamento pós-metafísico de Gianni Vattimo. In: ROCHA, Abdruschin Schaeffer et al. (Orgs.). Espiritualidades contemporâneas. Vitória: Unida; Faculdade Unida de Vitória, 2013. p. 63-75.

${ }^{28}$ ROSA, 2013, p. 63.

${ }^{29}$ ROSA, 2013, p. 63.

${ }^{30}$ ROSA, 2013, p. 64.

${ }^{31}$ ROSA, 2013, p. 66.

32 ROSA, 2013, p. 72. 
partir de Vattimo e John Caputo, de uma "frágil transcendência" 33 quando "o cristianismo, assim secularizado, torna-se em uma espiritualidade, em vez de uma religião, e sua expressão concreta é o amor ao próximo"34.

Fica implícito, a partir dos autores, que a definição contemporânea sobre espiritualidade se volta mais para a vivência da religião do que para seus aspectos institucionais. A espiritualidade tem, no seu arcabouço teórico, uma frustração com a modernidade, ancorada pelo Iluminismo, que não resolveu os problemas a que se propôs, contribuindo, assim, para um retorno à experiência religiosa, bem como para a relevância e a importância da espiritualidade nos seus mais diversos contextos. Exemplo disso é a vivência da espiritualidade no mundo do trabalho, apontada pelo teólogo Abdruschin Schaeffer Rocha. Tendo como eixo epistemológico a "espiritualidade laica", Rocha apresenta as novas formas de experimentar o sagrado e sua importância:

Percebe-se, então, que essa espiritualidade laica, à medida que se desvincula das amarras institucionais, "libera" o sagrado para que também seja vivenciado em ambientes profanos. Isso indica, sim, um retorno do religioso, como vimos na primeira seção, mas de um tipo difuso, instigador de um clima espiritual que produz consequências sobre os modos de vida, in-formando as maneiras de ser-no-mundo ${ }^{35}$.

Esses novos contextos envolvem a relevância e a importância da espiritualidade no contexto de saúde física e psíquica do indivíduo em diálogo com a medicina integrativa.

\section{Medicina integrativa e coping religioso: a saúde integral do ser humano}

\section{Medicina integrativa}

Otani e Barros apresentam uma pesquisa de 36 trabalhos, destacando a relevância da discussão da medicina integrativa no debate das medicinas alternativas e complementares. ${ }^{36}$ Essa pesquisa reuniu várias definições sobre medicina integrativa, apresentou a diferenciação de termos de medicina integrativa e medicina complementar, seu surgimento a partir de 1960, apontando para uma mudança de paradigma no modelo biomédico adotado no Ocidente, provocado, dentre outros fatores, pela

${ }^{33}$ ZABATIERO, Júlio Paulo Tavares. Espiritualidade frágil: Viver sob a ótica do reino de Deus. In: ROCHA et al. (Orgs.), 2013, p. 79.

${ }^{34}$ ZABATIERO, 2013, p. 79, 80.

${ }^{35}$ ROCHA, Abdruschin Schaeffer. Espiritualidade em ambientes corporativos: uma nova modalidade de retorno do religioso. In: ROCHA et al. (Orgs.), 2013, p. 15-31.

${ }^{36}$ OTANI, Márcia Aparecida Padovan; BARROS, Nelson Filice de. A Medicina Integrativa e a construção de um novo modelo na saúde. Ciência \& Saúde Coletiva, Rio de Janeiro, v. 16, n. 3, p. 1.801-1.811, mar. 2011. p. 1.802 
crítica à relação assimétrica de poder entre médicos e pacientes, em que o profissional não fornece informações suficientes sobre o tratamento e cura do paciente; consciência de que a medicina convencional é deficiente para solucionar determinadas doenças, especialmente as crônicas; insatisfação com o funcionamento do sistema de saúde moderno, que inclui grandes listas de espera e restrições financeiras; informação sobre o perigo dos efeitos colaterais dos medicamentos e das intervenções cirúrgicas ${ }^{37}$.

A medicina integrativa nasce como um modelo oposto ao modelo biomédico. Enquanto este investe para desenvolver a dimensão diagnóstica e aprofundar a explicação biológica, a medicina alternativa, como era denominada, volta-se para a dimensão da terapêutica, aprofundando-se nos problemas explicados pelas teorias do estilo de vida e ambiental. Essa mudança de paradigma trouxe conflitos entre os profissionais de saúde. Por isso, no final de 1980, nos Estados Unidos, para amenizar tais conflitos, foi adotada a denominação medicina complementar, que significa "complemento", ou seja, "que sucede ao elementar", havendo assim a possibilidade de associação de modelos, fundada em conjunções aditivas ("e...e") em detrimento das conjunções alternativas ("ou...ou"). ${ }^{38} \mathrm{O}$ termo medicina integrativa foi criado no final da década de 1990 na tentativa de descrever um novo modelo de saúde que retrate a integração dos diversos modelos terapêuticos e que ofereça cuidado integral à saúde. ${ }^{39}$

Os princípios fundamentais da medicina integrativa estão pautados na relação terapêutica, na abordagem do paciente como um todo, na orientação para a cura e na participação do paciente no tratamento. ${ }^{40}$ Tais princípios têm como base de intervenção a visão holística do ser humano, focando não apenas a doença em si, mas também a mente, o corpo e o espírito. Assim, na proposta desse novo modelo médico, está a participação ativa do paciente no processo de cura; a integração de modelos biopsicossociais, levando em consideração a experiência humana do indivíduo; o uso apropriado tanto de terapias convencionais como de terapias alternativas, permitindo aos médicos considerarem as condições genéticas, ambientais, nutricionais, psicossociais, estressantes e as crenças de cada paciente. ${ }^{41}$ Em outras palavras, na medicina integrativa a ênfase recai sobre a existência do ser humano nas suas múltiplas e indissociáveis dimensões.

Sob o olhar da formação médica, Lampert investiga a implementação dos programas curriculares em 12 escolas médicas brasileiras, divididas em modelos curriculares tradicionais e inovadores, propondo, a partir do modelo inovador, mudanças do paradigma flexneriano ${ }^{42}$ para o paradigma da integralidade. A seu ver, a maneira como

${ }^{37}$ GIDDENS, 2005 apud OTANI; BARROS, 2011, p. 1.802.

${ }^{38}$ BARROS, 2000 apud OTANI; BARROS, 2011, p. 1.802.

${ }^{39}$ OTANI; BARROS, 2011, p. 1.802 .

${ }^{40}$ OTANI; BARROS, 2011, p. 1.803.

${ }^{41}$ OTANI; BARROS, 2011, p. 1.805-1.808. Mediante revisão sistemática de literatura, os autores fazem várias definições sobre a medicina integrativa destacando a integração desta com a medicina convencional no processo de cura.

${ }^{42} \mathrm{O}$ modelo flexneriano foi um documento elaborado por Abraham Flexner com o objetivo de regularizar o poder médico e, dessa forma, reforçar a luta pelo ideário científico da medicina, estabelecendo regras para o desenvolvimento do ensino nas escolas médicas. 
são montados os currículos nas escolas médicas tem repercussão direta na atuação do formando e nas necessidades básicas da saúde (NBS). ${ }^{43}$ Há uma crítica ao modelo curricular de base flexneriano, que fragmenta o conhecimento em especialidades na forma de disciplinas isoladas que pouco interagem, descuidando "da abordagem da saúde do ser humano como um todo, inteiro e único no seu contexto" ${ }^{44}$. Embora reconheça os passos lentos em que se dão as mudanças paradigmáticas no modelo médico no Brasil, tal crítica apresenta alguns elementos que deveriam contemplar os currículos na formação médica para uma atuação mais humanizada no atendimento à saúde. Dentre esses elementos, destacam-se:

(a) o processo saúde-doença deve enfatizar mais a saúde do que a doença (a promoção, a preservação e a recuperação da saúde, sendo a doença um desvio, uma intercorrência na saúde, que deve ser evitada e, quando diagnosticada, eliminada em qualquer estágio evolutivo em que se encontre); (b) o processo ensino-aprendizagem deve estar mais centrado no aluno e em seu papel ativo na própria formação; (c) o ensino da prática deve se dar no sistema de saúde existente em graus crescentes de complexidade, voltado para as necessidades básicas de saúde, dentro de uma visão intersetorial de seus determinantes e da importância das referências e contra-referências entre os níveis de atenção; (d) a capacitação docente deve voltar-se tanto para a competência técnico-científica quanto para a competência didático-pedagógica, e para a participação e comprometimento no sistema público de saúde. Isso se refere à formação e reciclagem dos profissionais médicos, assim como à formulação e avaliação das políticas, dos serviços e do próprio sistema; e (e) o acompanhamento da dinâmica do mercado de trabalho médico deve estar orientado pela reflexão e discussão crítica dos aspectos econômicos e humanísticos da prestação de serviços de saúde e de suas implicações éticas ${ }^{45}$.

Fica explícito, nesse processo de mudança, o apelo para uma reformulação no projeto pedagógico das escolas de medicina. Segundo Lampert, no paradigma da integralidade, buscando uma gestão de qualidade na formação dos médicos, deve-se

[...] levar em conta os agentes do processo (o médico, a escola, o serviço) junto com o objeto da atenção (o paciente, o usuário, o cidadão, a coletividade), até hoje com pouco espaço para expressar sua contribuição, e junto com os meios de trabalho (complexo industrial provedor de equipamentos e insumos) $)^{46}$.

Nessa discussão, são apresentados alguns pontos que contribuem para o diálogo da espiritualidade no debate público sobre saúde. Dentre eles estão: a necessidade

${ }^{43}$ LAMPERT, Jadete Barbosa. Tendências de mudanças na formação médica no Brasil. 2002. 219f. Tese (Doutorado) - Fundação Osvaldo Cruz, Escola Nacional de Saúde Pública, Rio de Janeiro, 2002. p. 06, $12,24$.

44 LAMPERT, 2002, p. 12.

45 LAMPERT, 2002, p. 14.

${ }^{46}$ LAMPERT, 2002, p. 16. 
do médico olhar a doença e a pessoa que porta a doença ${ }^{47}$; uma base curricular "guiada por abordagens sociológicas, políticas e epistemológicas"48, configurando "um artefato social e cultural, isto é, localizado no âmbito das determinações sociais, históricas e de seu contexto" ${ }^{49}$; um ensino em função de prática liberal, cujo "ambiente educacional oferecerá, a docentes e alunos, modalidades alternativas de prática médica mais integralizada" 50 . Essas assertivas permitem "compreender as várias dimensões do processo saúde/doença" 51 , abrindo portas para abordagens interdisciplinares e multidisciplinares.

Numa perspectiva histórica, tanto a era pré-flexnoriana como o modelo flexnoriano tinham, como objetivo, a regularização do ato médico, bem como atender aos interesses sociais do mundo industrializado, tais como Inglaterra, França, Alemanha e os Estados Unidos. ${ }^{52}$ Alguns fatores foram decisivos para a consolidação desse modelo, entre eles, os fluxos migratórios desordenados, que provocaram várias epidemias e condições de vida precárias entre os pobres na era pré-flexnoriana ${ }^{53}$, e o avanço tecnológico no setor da saúde. A partir de então, no século XIX, a pessoa passa "a exercer um papel ativo e potencialmente eficaz na luta contra as doenças e o sofrimento do próprio homem" 54 . Essa medicina tem como pressuposto epistemológico a ciência cartesiana e os ideais positivistas do século XIX. ${ }^{55}$

No contexto dessa discussão histórica sobre a regularização do poder médico, duas questões são relevantes: o conflito, nos Estados Unidos, entre os médicos reguladores e os médicos práticos ou empiristas, o qual foi estabelecido pelo ideal positivista da saúde, que "opunha-se às práticas usuais da medicina americana em fins de século XIX" ${ }^{56}$; e a tecnificação do ato médico, que legitimou o mecanicismo e o biologicismo, conforme descrito abaixo:

A exclusão de práticas alternativas foi necessária para a viabilização da medicina científica. Essa firmou-se como eficaz porque era comprovada cientificamente, ao contrário das práticas baseadas no empiricismo ou no curandeirismo. A tecnificação do ato médico legitima o mecanicismo e o biologicismo citados anteriormente ao alijar do processo de trabalho o componente não-científico das relações humanas. A difusão da

${ }^{47}$ LAMPERT, 2002, p. 20. Tanto os conhecimentos cognitivos, técnicos e habilidades como a postura do profissional são relevantes na abordagem do paciente. Faz-se uma crítica à postura profissional que se volta mais para o diagnóstico do que para a pessoa que porta a enfermidade.

48 LAMPERT, 2002, p. 22.

49 LAMPERT, 2002, p. 22.

${ }^{50}$ LAMPERT, 2002, p. 24-25.

${ }^{51}$ LAMPERT, 2002, p. 25.

52 AGUIAR, Raphael Augusto Teixeira de. A construção internacional do conceito de atenção primária à saúde (APS) e sua influência na emergência e consolidação do Sistema Único de Saúde no Brasil. 2003. Dissertação (Mestrado) - Faculdade de Medicina da Universidade Federal de Minas Gerais, Belo Horizonte, 2003. p. 12-15.

53 SILVA JÚNIOR, 1998 apud AGUIAR, 2003, p. 12.

${ }^{54}$ CAMPOS, 2002 apud AGUIAR, 2003, p. 14, 15.

55 AGUIAR, 2003, p. 16.

56 AGUIAR, 2003, p. 16. 
tecnologia contribui para a progressividade do uso da técnica científica em detrimento da percepção dos sentidos ${ }^{57}$.

O modelo flexnoriano foi fundamental para a descoberta de solução para várias doenças, como também para afastar o ato médico do charlatanismo que imperava no contexto em que o relatório foi criado. Todavia, há críticas a esse modelo, a partir do próprio contexto em que foi elaborado o documento Flexner para os novos contextos da atualidade, analisado pelo viés da transição da medicina científica e da transição epidemiológica. ${ }^{58} \mathrm{Na}$ discussão entre os autores, tais como Omram, é apresentado um novo paradigma que não nega a importância e a relevância da tecnologia na vida do ser humano, mas que atribui a diminuição de fecundidade e de mortalidade a fatores ecobiológicos e socioeconômicos. ${ }^{59}$ Para Illich, outras doenças, como a febre tifoide, a cólera, a disenteria, a escarlatina, a difteria e o sarampo, seguiram o mesmo padrão da tuberculose, alcançando um pico de mortalidade e diminuindo independentemente de controle médico. ${ }^{60}$ Lalonde afirma:

a medicina científica, devido ao estímulo dispensado à pesquisa - bem como ao contexto anterior à transição epidemiológica - volta-se para a cura e não para o cuidado (care) contínuo e humanizado dos pacientes crônicos, cada vez mais necessário. A falta de um vínculo mais aprofundado entre o profissional responsável pela atenção médica e o doente é prejudicial ao acompanhamento de portadores de patologias crônicas, pois torna mais difícil o monitoramento da história natural da doença, sua evolução clínica e o entendimento de seus determinantes sócio-ambientais ${ }^{61}$.

Sob o olhar da psicologia social, Spink faz uma associação entre o processo de adoecimento e o contexto social, fortalecendo o ponto de vista para compreensão do processo de adoecimento e das práticas adotadas para a prevenção do adoecer, sua cura ou a promoção do estado de saúde, partindo de uma concepção psicossocial específica. A partir de uma análise construtivista e histórica, desloca-se o arcabouço epistemológico de retórica da verdade científica para a natureza construída da realidade social. O sujeito é visto como produto e produtor da realidade social, um ser ativo, que dá sentido aos objetos sociais e materiais que o cercam. $\mathrm{O}$ seu pressuposto teórico é abordar a doença não apenas como uma experiência individual, mas também como um fenômeno coletivo sujeito às forças ideológicas da sociedade. ${ }^{62}$

57 AGUIAR, 2003, p. 19.

58 AGUIAR, 2003, p. 20-23.

59 OMRAN, 1971 apud AGUIAR, 2003, p. 22.

${ }^{60}$ ILLICH, 1975 apud AGUIAR, 2002, p. 23.

${ }^{61}$ LALONDE, 1974 apud AGUIAR, 2003, p. 24.

${ }^{62}$ SPINK. Mary Jane P. Psicologia Social e Saúde: práticas, saberes e sentidos. Petrópolis: Vozes, 2003. p. $40-50$. 
Costa e Brandão falam de uma intervenção clínica que ocorre num contexto social/comunitário. ${ }^{63}$ Vincent de Gaulejac ${ }^{64}$, teórico da sociologia clínica, analisa a constituição humana como produto tanto dos determinantes psíquicos como sociais, não sendo tais determinantes dissociáveis. $\mathrm{O}$ autor ainda afirma que os determinantes sociais produzem um efeito psicológico que não pode ser compreendido apenas em sua dimensão individual, e que não se pode deixar de ver como as questões sociais e econômicas influenciam a forma como os indivíduos se organizam em sociedade.

A professora Bader Burihan Sawaia considera o sofrimento humano pela perspectiva ético-política, produzido por uma história de desigualdades e de injustiças sociais, vivenciado pelo indivíduo, mas que tem origem nas relações intersubjetivas constituídas socialmente. A partir do eixo da psicologia social comunitária e da psicologia sócio-histórica, o sofrimento não é visto como algo interno do ser humano, posição defendida até então pela psicologia tradicional, mas como algo construído a partir da relação do ser humano com o mundo material e social, mundo que só existe pela atividade humana. ${ }^{65}$

Considerando tais proposições, a medicina integrativa: ${ }^{66}$

- Considera todos os fatores que influenciam a manutenção da saúde e o aparecimento das doenças, inclusive o corpo, a mente e o espírito, bem como a comunidade (apoio social).

- Reconhece que a boa medicina precisa ser baseada em boa ciência, devendo ser investigativa e aberta a novos paradigmas.

- Usa métodos e terapêuticas naturais, efetivos e não invasivos, sempre que possível.

- Observa que a compaixão é sempre favorável, mesmo quando as terapias médicas não o são.

- Propõe uma abordagem transdisciplinar e transcultural comprometida com o processo de autoconhecimento e de desenvolvimento.

Por meio da quebra do paradigma do poder médico e pelo processo de adoecer como fenômeno histórico-social, pode-se inferir a discussão da espiritualidade no contexto de saúde. Dois argumentos podem validar essa assertiva: a prática da medicina integrativa como coadjuvante no processo de cura e o coping religioso no enfrentamento de demandas psíquicas. Quanto ao primeiro, dois autores, Cardoso ${ }^{67} \mathrm{e}$

${ }^{63}$ COSTA, Liana Fortunato; BRANDÃO, Shyrlene Nunes. Abordagem clínica no contexto comunitário: uma perspectiva integradora. Psicologia \& Sociedade, v. 17, n. 2, p. 33-41, maio/ago. 2005. p. 33.

${ }^{64}$ GAUJELAC, 2001 apud COSTA; BRANDÃO, 2005, p. 35.

${ }^{65}$ SAWAIA, 2000 apud COSTA; BRANDÃO, 2005, p. 35.

${ }^{66}$ LIMA, Paulo de Tarso. Medicina integrativa: a cura pelo equilíbrio. São Paulo: MG Editores, 2009. p. 23.

${ }^{67}$ CARDOSO, Roberto. Medicina e meditação: um médico ensina a meditar. São Paulo: MG Editores, 2015. 147 p. O autor é médico, especialista em ginecologia e obstetrícia; é mestre em obstetrícia e doutor em ciências pela Universidade Federal de São Paulo. Desenvolve pesquisas na Escola Paulista de Medicina sobre medicina comportamental e qualidade de vida. 
Koenig ${ }^{68}$, ambos militando na área médica, um do Brasil e outro do EUA, desenvolvem pesquisas mostrando a importância e a relevância da espiritualidade na promoção da saúde do indivíduo.

$\operatorname{Cardoso}^{69}$ demonstra que a meditação, desvinculada do "pacote" religioso, mas igualmente praticada com "conotação espiritual", pode atuar como "recurso terapêutico". Dois tipos de meditação são apresentados pelo autor e são de cunho místico-religioso: "Meditações ativas de movimento e meditações passivas concentrativas". Em ambas as meditações, estão presentes elementos devocionais exemplificados na "reverência da prece maometana" ou no "olhar ou imaginar o rosto de Buda, ou Jesus", sendo a meditação passiva concentrativa a mais utilizada na literatura médica. ${ }^{70}$ São apresentados resultados de pesquisas que apontam os efeitos psicofísicos da meditação, como redução da frequência cardíaca, redução do metabolismo, ação sobre o sistema nervoso autônomo, redução dos níveis de cortisol, aldosterona e noradrenalina (substâncias ligadas ao estresse) e aumento dos níveis de outras substâncias, como a serotonina (hormônio ligado ao bem-estar). Segundo o autor, os efeitos psíquicos também se fazem presentes, tais como o relaxamento psíquico, a vivência positiva, a sensação de "paz interna", sensação de felicidade, impressão de harmonia com o mundo, menor tendência à perda do controle. ${ }^{71}$

Benson apresenta as possíveis contribuições da meditação para diferentes problemas de saúde, apontando seu uso no tratamento da hipertensão arterial e na dependência de drogas ilícitas. ${ }^{72}$ Em 1982, numa revisão de literatura, o mesmo autor ressaltou o valor preventivo e terapêutico da meditação. ${ }^{73}$ Pesquisas de autores como Sudsuang et alii, Barnes, Patel et alii, Wenneberg et alii, Walton et alii, Miller et alii e outros, cada qual numa perspectiva diferente, demonstraram resultados significativos da meditação em indivíduos com alto risco de problemas coronarianos, diminuição da ansiedade e da depressão, redução da dor crônica, flexibilidade cognitiva e mental em idosos, melhora nos sintomas físicos, emocionais e na vida social. ${ }^{74}$

Por outra linha de raciocínio, mas numa mesma direção, Koenig ${ }^{75}$ considera a importância e a relevância da espiritualidade como coadjuvante no tratamento dos pacientes. Em sua assertiva, é possível detectar o possível diálogo entre espiritualidade e medicina integrativa. Por meio de quatro perguntas - por que, como, quando e $o$

${ }^{68}$ KOENIG, Harold G. Espiritualidade no cuidado com o paciente - por que, como, quando e o quê. Tradução Giovana Campos. São Paulo: FE Editora Jornalística Ltda., 2012. 136p. O autor estuda a ligação entre fé e saúde desde o início dos anos 1980, quando ainda era clínico geral, demonstrando que as pessoas que praticam ativamente o seu lado espiritual ou religioso adoecem menos e, quando ficam doentes, têm uma evolução melhor da doença do que as que não cultivam essa faceta mais transcendental da vida.

${ }^{69}$ CARDOSO, 2015, p. 15-26.

70 CARDOSO, 2015, p. 49-53.

${ }^{71}$ CARDOSO, 2015, p. 119-127.

72 BENSON et al., 1974 apud CARDOSO, 2015, p. 129.

73 BENSON, 1982 apud CARDOSO, 2015, p. 129.

${ }^{74}$ CARDOSO, 2015, p. 129-134. O autor, a partir de diversos outros autores ligados à pesquisa de campo, demonstra a relevância da meditação no campo da saúde em seu mais variado contexto.

${ }^{75}$ KOENIG, 2012, p. 6-15. 
$q u \hat{e}$ - Koenig ressalta os motivos pelos quais os médicos deveriam levar a espiritualidade em consideração, bem como enfatiza a importância do processo de avaliação espiritual do paciente e da história espiritual durante o tratamento. Não ficam fora de sua discussão os resultados esperados dos cuidados espirituais e os efeitos negativos que a religião pode exercer sobre a saúde. Pesquisas apontaram que pessoas portadoras de doenças coronárias, artrite, doenças renais, fibromas císticos, diabetes, câncer, câncer ginecológico, HIV/AIDS, dores crônicas, doenças terminais" "76 buscam apoio e conforto nas crenças religiosas. Daí a importância e a relevância da espiritualidade no contexto de tratamento dos pacientes. Na perspectiva do autor, "negligenciar a dimensão espiritual é como ignorar o ambiente social de um paciente ou seu estado psicológico, e resulta em falhar ao tratar a pessoa 'integralmente" "'77, postulado teórico da medicina integrativa. ${ }^{78}$ Estendendo o conceito de relação médico/paciente, tomando como base teórica a medicina integrativa, Koenig mostrou, a partir de estudo de 177 pacientes ambulatoriais numa clínica pneumológica, no hospital da Universidade da Pensilvânia, "que quase metade desses pacientes (45\%) revelou que suas crenças religiosas influenciariam as decisões médicas caso se tornassem gravemente enfermos" ${ }^{\text {"79 }}$.

Historicamente, a partir do raciocínio da cultura da medicina chinesa, tibetana e ayurvédica, o psiquiatra Paulo Bloise afirma que "a manutenção da saúde e o aparecimento da doença dependem da interação mente, corpo e espírito" "80'. Hipócrates, no século IV a.C., já possuía uma visão complexa do ser humano, postulando "que a doença era influenciada pelo ambiente, pelo clima, pela dieta e pelo modo de viver" hipótese que foi descartada no século XVII. Na ocasião, o desenvolvimento da compreensão dualística corpo e mente foi investigado por instâncias diferentes: mente e alma pela filosofia e a religião; o corpo pela medicina. Não se acreditava que a mente e a alma interferiam nos processos físicos. No século XIX, esse conceito é questionado pela psicologia e pela psiquiatria. Tal questionamento se dá a partir do conceito de "psicogênese, em que fatores psicológicos afetam o corpo" ${ }^{2} \mathrm{e}$ da "medicina psicossomática estruturada no século XX", em que "fatores sociais e psicológicos foram considerados importantes na etiologia e na manutenção de inúmeras doenças" ${ }^{83}$

Esse autor trabalha o conceito e a importância da espiritualidade no contexto da medicina integrativa. ${ }^{84}$ Mesmo lidando com as complexidades de conceito dos ter-

${ }^{76}$ KOENIG, 2012, p. 17.

${ }^{77}$ KOENIG, 2012, p. 16.

${ }^{78}$ OTANI; BARROS, 2011, p. 1.803.

${ }^{79}$ KOENIG, 2012, p. 18. Nessa pesquisa, realizada por Ehaman et al., conforme referência bibliográfica de Koenig, foi demonstrado que as crenças religiosas ajudam os pacientes a aceitar os procedimentos médicos, e a religião pode influenciar decisões médicas sobre a continuidade da vida. Para maiores esclarecimentos pode-se consultar o capítulo 1 - Por que incluir a espiritualidade?

${ }^{80}$ BLOISE, Paulo. Medicina integrativa: corpo, mente e espiritualidade. In: BLOISE, Paulo (Org.). Saúde integral: a medicina do corpo, da mente e o papel da espiritualidade. São Paulo: Senac, 2011. p. 136.

${ }^{81}$ BLOISE, 2011, p. 136.

${ }^{82}$ BLOISE, 2011, p. 137.

${ }^{83}$ BLOISE, 2011, p. 137.

${ }^{84}$ BLOISE, 2011, p. 135-164. 
mos religião e espiritualidade, bem como com a dificuldade de lidar com essa questão em termos científicos, pois "como operacionalizar a espiritualidade?" 85 , o autor afirma que a importância da espiritualidade é reconhecida pela Associação Psiquiátrica Americana (APA - American Psychiatric Association). Essa associação "sugere aos psicoterapeutas determinados procedimentos para abordarem o assunto" "86, sendo um desses, em uma anamnese clínica, a compreensão sobre o que motiva o indivíduo para a espiritualidade.

Assim, a inter-relação entre espiritualidade e medicina integrativa, conforme proposto pelo autor, tem por base as definições de espiritualidade adotada nesta pesquisa e também o conceito de medicina integrativa como uma "aproximação entre diferentes elementos" ${ }^{87}$, levando em conta a pessoa como um todo (corpo, mente, espírito), com o objetivo de "restabelecer a saúde" ${ }^{88}$, questões consideradas anteriormente. Tanto Koenig ${ }^{89}$ como Bloise $^{90}$, em perspectivas diferentes, ao tratarem a relação médico-paciente, abordam duas questões relevantes: a questão da humanização, quando se deve levar em conta o paciente e suas crenças e não apenas a especialização médica, e a questão do paciente como um agente ativo, tornando-o responsável por seu tratamento. Alinhando as duas abordagens às características de um curador, proposto por Larry Dossey, e ao princípio básico das "terapias psicobiológicas", segundo Ernest L. Rossi, pode-se inferir o papel da espiritualidade no contexto de medicina integrativa. Larry Dossey sugere que:

a eficácia de algumas técnicas empregadas na medicina mente-corpo varia com a compaixão, a empatia e a habilidade de estar inteiramente presente durante a atividade. A compaixão [...] seria a possibilidade de sofrer com o outro, usualmente acompanhada pelo desejo de ajudar; a empatia relaciona-se à habilidade de entender, de identificar-se com sentimentos e dificuldades alheias ${ }^{91}$.

Considerando que o paciente ativo auxilia na intervenção médica, Ernest L. Rossi afirma que um dos princípios básicos das terapias psicobiológicas seria "converter o estresse negativo de ameaça em uma experiência positiva de defrontar-se com o desafio"92. Ambos os autores, Dossey com o pressuposto "humanização do curador" e Rossi com a abordagem das "terapias psicobiológicas", apontam, por indução do pesquisador, para elementos conceituais presentes na espiritualidade, que, segundo autores como Underwood e Teresi ${ }^{93}$, Peçanha e Silva ${ }^{94}$, Paiva ${ }^{95}$ e outros, é vista e estu-

\footnotetext{
${ }^{85}$ BLOISE, 2011, p. 146.

${ }^{86}$ BLOISE, 2011, p. 145.

87 BLOISE, 2011, p. 137.

88 BLOISE, 2011, p. 137, 138.

89 KOENIG, 2012, p. 31-42.

${ }^{90}$ BLOISE, 2011, p. 151-153.

91 DOSSEY, 2008 apud BLOISE, 2011, p. 152.

92 ROSSI, 1994 apud BLOISE, 2011, p. 153.

93 UNDERWOOD; TERESI, 2002 apud PEÇANHA; SILVA, 2005, p. 8.

94 PEÇANHA; SILVA, 2005, p. 9.

95 PAIVA, 2011, p. 1-7.
} 
dada pelo viés do amor ao próximo, como oferecedora de suporte ao indivíduo, ajuda mútua, autorrealização, potencialidade para superação dos traumas, trazendo sentido e propósito de vida, o que reitera a importância e a relevância da espiritualidade em interface com a medicina integrativa.

Tomando por base esse conceito de potencialização como espiritualidade, sua importância e relevância estendem-se para outros campos.

\section{Coping religioso}

Se, por um lado, conforme visto anteriormente, as crenças religiosas são coadjuvantes no processo de cura para várias enfermidades, ora funcionando na aceitação dos procedimentos médicos, ora funcionando no papel ativo do paciente por meio da medicina integrativa, por outro lado, a espiritualidade também tem impacto na saúde mental, conforme abordado por Moreira-Almeida e Stroppa. ${ }^{96} \mathrm{Na}$ análise dos autores, com o objetivo de considerar os efeitos positivos da $\mathrm{RE}^{97}$ na saúde, faz-se uma revisão de conceito entre "religiosidade intrínseca" e "religiosidade extrínseca", para então considerar o coping no contexto de saúde mental. ${ }^{98}$ A expressão coping não tem uma tradução exata para a língua portuguesa, "mas pode significar lidar, manejar, adaptar-se ou enfrentar. Trata-se de um processo de interação entre o indivíduo e o ambiente, com a função de reduzir ou suportar uma situação adversa que exceda os recursos do individuo"99. Assim, "Coping religioso e espiritual (CRE) é o modo como as pessoas utilizam sua RE para lidar com situações de estresse e de dificuldade em suas vidas" 100 . Os autores enfatizam "a relação do RE com transtornos depressivos, transtornos de ansiedade, transtorno afetivo bipolar, esquizofrenia, dependência de substâncias e suicídio"101.

Sob a ótica do coping religioso positivo, descartando aqueles elementos em que a religiosidade contribui para o estresse psicológico e até como fator preditor da evolução de transtornos depressivos, Moreira-Almeida e Stroppa, a partir de pesquisas investigativas com paciente idosos, hospitalizados ou não, realizadas por Koenig el alii, afirmam:

Recursos de Coping como suporte social e vivência religiosa podem facilitar a adaptação de pacientes às limitações impostas pela doença, reduzindo os efeitos sobre a ocorrência e a recorrência da depressão. RE pode proporcionar uma visão de mundo em

\footnotetext{
96 MOREIRA-ALMEIDA, Alexander; STROPPA, André. Espiritualidade e Saúde Mental: Importância e impacto da espiritualidade na saúde mental. Zen Review, v. 2, p. 2-6, 2010. p. 2. Disponível em: <http:// www.hoje.org.br/arq/artigos/Espiritual2.pdf>. Acesso em: 04 ago. 2014.

97 Sigla correspondente a Religiosidade/Espiritualidade.

98 ALLPORT, 1967 apud MOREIRA-ALMEIDDA; STROPPA, 2010, p. 2.

99 ALLPORT, 1967 apud MOREIRA-ALMEIDA; STROPPA, 2010, p. 2.

${ }^{100}$ ALLPORT, 1967 apud MOREIRA-ALMEIDA; STROPPA, 2010, p. 3.

${ }^{101}$ KOENIG, 1998 apud MOREIRA-ALMEIDA; STROPPA, 2010, p. 3.
} 
que doença, sofrimento e morte tenham melhor aceitação e compreensão. Pode oferecer maior autoestima e maior resiliência, que normalmente declinam com a idade ${ }^{102}$.

Panzini e Bandeira, por meio de revisão de literatura sobre coping religioso e espiritual entre 1979 e 2006, afirmam que "o coping religioso/espiritual (CRE), pouco estudado no Brasil, está associado à saúde e à qualidade de vida (QV)", corroborando o pensamento de que as estratégias de coping religioso e espiritual podem ser classificadas como "positivas" ou "negativas", tendo no coping religioso e espiritual positivo uma maior aderência no enfrentamento das crises. Conforme abordado pelas autoras, uma vez que esse recurso seja utilizado, poderá ocorrer redução de custos de intervenção em termos de saúde pública. ${ }^{103}$ Conectando religião/espiritualidade à saúde, tanto física como mental, o coping religioso apresenta-se como o construto mais utilizado para se fazer tal conexão. Por isso, de quase 850 pesquisas examinando a relação da religiosidade/espiritualidade com a saúde mental,

a maioria endossa associação do envolvimento religioso com maiores níveis de satisfação de vida, bem-estar, senso de propósito e significado da vida, esperança, otimismo, estabilidade nos casamentos e menores índices de ansiedade, depressão e abuso de substâncias ${ }^{104}$.

Considerando tais conexões e associações entre saúde e espiritualidade e resguardando os elementos negativos da religião, que contribuem mais para as patologias do que para a cura, o coping religioso/espiritual possibilitou uma mudança de paradigma no meio científico, na maneira de apresentar a religião, tendo como exemplo o manual Diagnóstico e Estatístico de Doenças Mentais IV, que "realizou mudanças significativas em sua apresentação da religião, removendo frequentes ilustrações negativas desta na psicopatologia e incluindo o Código V para Problemas Religiosos e Espirituais"105. Assim:

O conceito de coping religioso/espiritual está inserido nas áreas da psicologia cognitivo-comportamental, psicologia da religião, psicologia positiva, psicologia da saúde e do escopo de estudos sobre religião e saúde, medicina e espiritualidade, tendo sido delineado a partir do estudo cognitivista do estresse e do coping ${ }^{106}$.

O coping religioso/espiritual/positivo está presente no enfrentamento de outras enfermidades, tais como doença renal crônica ${ }^{107}$, inflamação intestinal (DII) associada

\footnotetext{
${ }^{102}$ MOREIRA-ALMEIDA; STROPPA, 2010, p. 4.

${ }^{103}$ PANZINI, R. G.; BANDEIRA, D. R. Revisão da Literatura: Coping(enfrentamento) religioso/espiritual. Revista Psiquiatria Clínica, n. 34, supl. 1, p. 126-135, 2007. p. 126.

${ }^{104}$ KOENIG, 2001 apud PANZINI; BANDEIRA, 2017, p. 127.

${ }^{105}$ WEAVER, 1998 apud PANZINI; BANDEIRA, 2007, p. 127.

${ }^{106}$ PANZINI; BANDEIRA, 2007, p. 128.

${ }^{107}$ VALCANTI, Carolina Costa et al. Coping religioso/espiritual em pessoas com doença renal crônica em tratamento hemodialítico. Revista da Escola de Enfermagem da USP, São Paulo, v. 46, n. 4, p. 838-845, 2012.
} 
a elevados níveis de ansiedade e depressão, além de uma reduzida qualidade de vida relacionada à saúde (QVRS). ${ }^{108}$

\section{Considerações finais}

Os estudos apontam para uma diferenciação conceitual entre religião, religiosidade e espiritualidade. Embora se admita a importância da religião em seus aspectos institucionais, fica evidente que é a vivência da espiritualidade, entendida como religião intrínseca, que será benéfica para a saúde integral do ser humano.

Nesse sentido, é possível pensar a espiritualidade em diálogo com outros campos do saber no debate público sobre saúde física e psíquica. Os argumentos da quebra de paradigma do modelo biomédico e a prática da medicina integrativa, em que a doença não é analisada apenas pelas especificidades médicas, mas como fenômeno histórico-social, valida essa assertiva.

Constatam-se, mediante pesquisas, os efeitos positivos da espiritualidade nos contextos de saúde física e psíquica, podendo atuar em nas abordagens multidisciplinar e interdisciplinar, em diversos contextos de saúde.

\section{Referências}

AGUIAR, Raphael Augusto Teixeira de. A construção internacional do conceito de atenção primária à saúde (APS) e sua influência na emergência e consolidação do Sistema Único de Saúde no Brasil. 2003. Dissertação (Mestrado) - Faculdade de Medicina da Universidade Federal de Minas Gerais, Belo Horizonte, 2003.

BLOISE, Paulo. Medicina integrativa: corpo, mente e espiritualidade. In: BLOISE, Paulo (Org.). Saúde integral: a medicina do corpo, da mente e o papel da espiritualidade. São Paulo: Senac, 2011. p. 135-164.

CARDOSO, Roberto. Medicina e meditação: um médico ensina a meditar. São Paulo: MG Editores, 2015.

COSTA, Liana Fortunato; BRANDÃO, Shyrlene Nunes. Abordagem clínica no contexto comunitário: uma perspectiva integradora. Psicologia \& Sociedade, v. 17, n. 2, p. 33-41, maio/ago. 2005. FARIA, Juliana Bernardes; SEIDL, Eliane Maria Fleury. Religiosidade e enfrentamento em contextos de saúde e doença: revisão da literatura. Psicologia: Reflexão e Crítica, v. 18, n. 3, p. 381-389, 2005.

FREITAS, Thiago Holanda. Influência do coping religioso-espiritual na qualidade de vida e adesão terapêutica de pacientes com doença inflamatória intestinal. 2014. 65 f. Dissertação (Mestrado em Ciências Médicas) - Universidade Federal do Ceará, Faculdade de Medicina, Fortaleza, 2014.

HOVESTOL, Tom. A neurose da religião: o desastre do extremismo religioso. Tradução Lena Aranha. (c2009). São Paulo: Hagnos, 2009.

KOENIG, Harold G. Espiritualidade no cuidado com o paciente: por que, como, quando e o quê. Tradução Giovana Campos. São Paulo: FE Editora Jornalística Ltda., 2005.

\footnotetext{
${ }^{108}$ FREITAS, Thiago Holanda. Influência do coping religioso-espiritual na qualidade de vida e adesão terapêutica de pacientes com doença inflamatória intestinal. 2014. 65f. Dissertação (Mestrado em Ciências Médicas) - Universidade Federal do Ceará, Faculdade de Medicina, Fortaleza, 2014.
} 
LAMPERT, Jadete Barbosa. Tendências de mudanças na formação médica no Brasil. 2002. 219f. Tese (Doutorado) - Fundação Osvaldo Cruz, Escola Nacional de Saúde Pública, Rio de Janeiro, 2002.

LIMA, Paulo de Tarso. Medicina integrativa: a cura pelo equilíbrio. São Paulo: MG Editores, 2009.

MOREIRA-ALMEIDA, Alexander; STROPPA, André. Espiritualidade e Saúde Mental: Importância e impacto da espiritualidade na saúde mental. Zen Review, v. 2, p. 2-6, 2010.

MULLER, Marisa Campio. Introdução. In: TEIXEIRA, Evilázio Francisco Borges et al. (Orgs.). Espiritualidade e qualidade de vida. Porto Alegre: EDIPUCRS, 2004. Disponível em: <http:// www.pucrs.br/edipucrs/digitalizacao/irmaosmaristas/espiritualidade.pdf $>$. Acesso em: 25 nov. 2015.

OTANI, Márcia Aparecida Padovan; BARROS, Nelson Filice de. A Medicina Integrativa e a construção de um novo modelo na saúde. Ciência \& Saúde Coletiva, Rio de Janeiro, v. 16, n. 3, p. 1.801-1.811, mar. 2011.

PAIVA. Geraldo José de. Psicologia e Espiritualidade. In: BERGER, Andrea Simone; TINOCO, Denise Hernandes; ABOU CHAHINE, Marien (Orgs.). Encontros na Psicologia. IV Congresso de Psicologia Unifil. I Congresso Nacional de Psicologia. Londrina: Ed. Unifil, 2011. p. 15-22.

PANZINI, R. G.; BANDEIRA, D. R. Revisão da Literatura: Coping (enfrentamento) religioso/ espiritual. Rev. Psiq. Clín. 34, supl. 1, p. 126-135, 2007.

PEÇANHA, Dóris Lieth; SILVA, Priscila Menezes da. Saúde mental: estudos sobre a contribuição da espiritualidade. Universidade Federal de São Carlos, Centro de Educação em Ciências Humanas, Departamento de Psicologia, [s.d.].

ROCHA, Abdruschin Schaeffer. Espiritualidade em ambientes corporativos: uma nova modalidade de retorno do religioso. In: ROCHA, Abdruschin Schaeffer et al. (Orgs.). Espiritualidades contemporâneas. Vitória: Unida; Faculdade Unida de Vitória, 2013.

ROSA, Wanderley Pereira da. Kênosis e espiritualidade: uma leitura a partir do pensamento pós-metafísico de Gianni Vattimo. In: ROCHA, Abdruschin Schaeffer et al. (Orgs.). Espiritualidades contemporâneas. Vitória: Unida; Faculdade Unida de Vitória, 2013.

RUTHES, Vanessa Roberta Massambani. A relação entre espiritualidade e saúde: um novo paradigma. Saberes em Ação. Revista de Estudos da Faculdade Messiânica, ano 2, n. 3, p. 8-13, jan./jun. 2014.

SPINK. Mary Jane P. Psicologia Social e Saúde: práticas, saberes e sentidos. Petrópolis: Vozes, 2003.

VALCANTI, Carolina Costa et al. Coping religioso/espiritual em pessoas com doença renal crônica em tratamento hemodialítico. Revista da Escola de Enfermagem da USP, São Paulo, v. 46, n. 4, p. 838-845, 2012.

VIEIRA, Carlos Alberto Pinheiro. A proposta de Gianni Vattimo para uma espiritualidade pós-metafísica. Paralellus, Recife, ano 3, n. 1, p. 189-204, jul./dez. 2012.

ZABATIERO, Júlio Paulo Tavares. Espiritualidade frágil: Viver sob a ótica do reino de Deus. In: ROCHA, Abdruschin Schaeffer et al. (Org.). Espiritualidades contemporâneas. Vitória: Unida; Faculdade Unida de Vitória, 2013. 